\title{
ANÁLISE ESPACIAL DA PRODUÇÃO DA SOJA E CAPACIDADE ESTÁTICA DE ARMAZENAMENTO NO ESTADO DO MATO GROSSO
}

\author{
SPATIAL ANALYSIS OF SOYBEAN PRODUCTION AND STATIC STOCKPILE \\ CAPABILITY IN MATO GROSSO STATE \\ Marcos Antônio de Oliveira ${ }^{1}$ \\ Rodrigo Cornacini Ferreira ${ }^{2}$ \\ Rubson Natal Ribeiro Sibaldelli ${ }^{3}$ \\ Sidnei Pereira do Nascimento ${ }^{4}$ \\ Aricieri Devidé Junior ${ }^{5}$
}

\begin{abstract}
RESUMO
O Brasil enfrenta problemas de infraestrutura de armazenagem de grãos. A soja, principal commodity agrícola brasileira, ganha destaque diante da necessidade energética mundial. $O$ objetivo deste estudo foi analisar a produção de soja e a capacidade estática da armazenagem a granel no Estado de Mato Grosso. Por meio da análise exploratória, os dados oficiais de produção, área plantada e capacidade estática, foram espacializados através de um Sistema de Informação Geográfica. O déficit de armazenagem foi analisado como um indicador imprescindível na busca racional das movimentações das safras e da implantação de políticas e tecnologias de armazenagem. Concluiu-se que a cultura da soja está consolidada com participação ativa na produção de grãos no estado de Mato Grosso. Todavia, faltam investimentos, planejamento e implantação de políticas públicas que criem racionalização nos processos e fluxos de pós-colheita, pois os indicadores demonstraram que diante de uma expansão planejada de armazéns a granel será possível minimizar as perdas no escoamento da produção. Isso hoje não é possível em relação à insuficiência de armazéns estáticos a granel para atendimento da produção atual, em especial ao potencial crescimento na produção deste importante estado agrícola brasileiro.
\end{abstract}

Palavras-chave: Armazéns. Escoamento. Produção agrícola.

JEL: 010

\section{ABSTRACT}

Brazil has faced problems related to grain storage infrastructure. Soybean, the main Brazilian agricultural commodity, is highlighted due to the worldwide energy demand. This study was aimed at analyzing the soybean production and the static capacity for bulk storage in the state of Mato Grosso. Through exploratory analysis, the official data of production, acreage and static capacity were spatialized using a Geographic Information System. The storage deficit

\footnotetext{
${ }^{1}$ Economista graduado pela Universidade Federal de Londrina (UEL). Analista da Embrapa Soja. E-mail: marcos.antonio@embrapa.br

${ }^{2}$ Doutorando em Agronomia pela Universidade Estadual de Londrina (UEL). E-mail: agrorcf@gmail.com

Mestrando em Engenharia Ambiental pela Universidade Tecnológica Federal - UTFPR. E-mail: rubson.sibaldelli@embrapa.br

4 Doutor em Economia pela Universidade de São Paulo (USP). Professor do Departamento de Economia da Universidade Estadual de Londrina (UEL). E-mail: sidnei@uel.br

5 Doutor em Economia pela Universidade Federal do Ceará (UFC). Professor do Departamento de Economia da Universidade Estadual de Londrina (UEL). E-mail: aridjr@uel.br
} 
was analyzed as an essential indicator in the rational pursuit of the crop transportation and of the deployment of storage policies and technologies. It was concluded that the soybean crop has been consolidated and has had an active participation in the grain production in the state of Mato Grosso. However, there is a lack of investments, planning and deployment of public policies that create streamlining in postharvest processes and flows since indicators have shown that a planned expansion of bulk warehouses can minimize losses in the distribution of production which has been currently impaired due to the scarcity of static bulk warehouses to meet the current production, especially the potential growth in the production of this important Brazilian agricultural state.

Keywords: Warehouses. Distribution. Agricultural production.

\section{JEL: A19; O47}

\section{INTRODUÇÃO}

De origem asiática, a soja (Glycine max L. Merrill) é uma das mais antigas plantas cultivadas, tornando-se atualmente um produto indispensável na indústria de transformação e na formulação de rações para criação de animais, o que pode apoiar e explicar várias transformações ocasionadas na agricultura e na alimentação ao longo da história.

No mercado mundial, a soja é um produto com fluxo físico e financeiro dinâmico nas relações internacionais. Sua transformação possibilita a obtenção de dois produtos principais. O primeiro é o óleo diferenciado, de cor clara, sem sabor, utilizado nas indústrias alimentícias, de lubrificantes, de combustível, de tintas, de fabricação de sabão, entre outras. O segundo é o resíduo (torta), ocupando o maior mercado da leguminosa, e possui alto grau de proteína (38\%), constituindo a base alimentar de animais, como frangos, suínos e bovinos (BERTRAND, LAURENT e LECLERCQ, 1987).

No ano agrícola 2012, sete países representaram 93\% da produção mundial de grãos de soja, sendo: Estados Unidos - EUA (31\%); Brasil (25\%); Argentina (20\%); China (10\%); Índia (4\%) e Paraguai (3\%). Verifica-se que os EUA vem perdendo este domínio. Em 1990, os EUA detinham 44\% da produção mundial de grãos e em 2012 participaram com 31\% - queda de 13\% no período.

Há mais de 22 anos o Brasil ocupa a $2^{\text {a }}$ colocação, sendo que em 1990 detinham 17\% da produção mundial e em 2012 atingiu 25\% - aumento de $8 \%$ no período. Dentre os setes países listados, a Argentina foi a que mais cresceu na participação. Em 1990 detinha 9\% da produção mundial e em 2012 atingiu $20 \%$ - aumento relativo de $11 \%$. Ao analisar a evolução da produção mundial de grãos de soja nos últimos 22 anos constatou-se um crescimento de $122 \%$. $\mathrm{Na}$ safra de 1990, a produção foi de 118 milhões de toneladas, atingindo na safra 2012 o patamar de 263 milhões toneladas. Neste mesmo período, houve incremento de $76 \%$ da área plantada, equivalente a 63 milhões de hectares no ano agrícola de 1990, e 111 milhões de hectares em 2012 (FAO, 2014).

Em números absolutos, o país que mais aumentou sua área de plantio foi à Argentina. No ano agrícola de 1990, eram 4,9 milhões, passando para 19 milhões de hectares em 2012 - incremento de 14 milhões de hectares. No 
Brasil, o ano agrícola de 1990 a área plantada foi de 11 milhões de hectares e em 2012 passou para 24 milhões de hectares - aumento de 13 milhões de hectares. Já os EUA aumentaram sua área de 22 milhões de hectares no ano agrícola 1990 para 30 milhões em 2012 - acréscimo de 8 milhões de hectares (FAO, 2014).

Entre os três maiores produtores, o Brasil apresentou incremento de $52 \%$ na produtividade. No ano agrícola de 1990, a produtividade foi de $1.732 \mathrm{~kg}$ $\mathrm{ha}^{-1}$, sendo que no ano agrícola de 2012 passou a $2.634 \mathrm{~kg} \mathrm{ha}^{-1}$. Argentina apresentou aumento de $23 \%$ na eficiência produtiva, passando de $2.156 \mathrm{~kg} \mathrm{ha}^{-}$ ${ }^{1}$ no ano agrícola de 1990 para $2.661 \mathrm{~kg} \mathrm{ha}^{-1}$ no ano agrícola de 2012. Enquanto que os EUA aumentaram sua eficiência em 16\%, com $2.292 \mathrm{~kg} \mathrm{ha}^{-1}$ em 1990 para $2.664 \mathrm{~kg} \mathrm{ha}^{-1}$ (BACEN, 2014).

Fukui e Lopes (2013) concluíram que no Brasil as expansões da área e da produtividade ocorreram graças à incorporação do conjunto de tecnologias no sistema produtivo, desenvolvido por centros de pesquisas e instituições de ensino. Assim, o Brasil ampliou o seu mercado, sendo que em 1990 participava com 4\% do valor total exportado e em 2012 este valor foi de $8 \%$. Ao analisar qual "Produto Soja" tem-se exportado, constatou-se que a maior participação é como "Produto Básico" (in natura).

Em 1990, a soja, mesmo triturada, participava de $11 \%$ do total comercializado, passando para $15 \%$ em 2012. No entanto, para o óleo de soja caracterizado como produto semimanufaturado houve uma constância na série analisada, permanecendo na faixa de 6\% entre os anos de 1990 e 2012 (BACEN, 2014), evidenciando que há uma elevação da participação dos produtos básicos na pauta de exportação. Isso é corroborado por Pessoa (2006) e ratificada por Fernandes Filho e Belik (2010), em que a mudança no padrão do indicador é explicada em parte pela incorporação da Lei Kandir, que equalizou as tarifas de exportação para produtos agrícolas in natura e produtos processados.

Após analisar a área, produtividade e impactos na pauta de exportação, pode-se ponderar a participação da soja no agronegócio brasileiro, sendo que na safra 2011, os principais cereais produzidos no Brasil foram: milho (44\%), soja $(40 \%)$, arroz $(7 \%)$ e trigo (3\%), ou seja, milho e soja representaram $84 \%$ da produção total. Sendo que o estado de Mato Grosso representou 19\% de toda a produção brasileira de grãos nesta safra.

O milho obteve esta posição em 2011, resultante de duas variáveis. A primeira foi o aumento da produção na safra de inverno, conhecida como $2^{a}$ safra. Na safra 1990 , a $2^{a}$ safra de milho representava $1 \%$ do total de grãos produzidos, sendo que em 2011 representou 24\%. Este índice é superior em $4 \%$ aos resultados obtidos na $1^{\text {a }}$ safra do mesmo ano. Ao analisar a safra de verão, identifica-se a tendência de aumento na participação da produção de soja. Na safra de 1990, representava $34 \%$ dos grãos produzidos e o milho $37 \%$.

No mesmo quesito, quando se analisa a safra verão 2011, a soja representou $40 \%$ da produção contra $20 \%$ do milho (CONAB, 2014). Percebese que o produtor rural está cultivando soja, na "safra verão", e milho, na "safra de inverno", um sistema de sucessão. Isso segundo Mascarenhas et al. (1993), aumenta a produtividade e conforme Melo; Silva e Esperancicni (2013), consolida a soja como uma opção mais atraente e de menor aversão ao risco. A segunda variável foi o clima, sendo a seca responsável pela quebra na 
produção de soja, o que a colocou no $2^{\circ}$ lugar do ranking nacional de produção de cereal (EMBRAPA TRIGO, 2012).

Os fatos evidenciados destacam a soja como principal leguminosa produzida no Brasil na atualidade. Como consequência esta cultura tem aumentando sua participação na economia. Segundo dados do Banco Central do Brasil (BACEN, 2014) e Instituto Brasileiro de Geografia e Estatística (IBGE, 2014), no ano 2000 a soja participava com $25 \%$ do PIB agropecuário e passou a representar $32,3 \%$ em 2011 - aumento de $28,0 \%$. Ao analisar o PIB nacional no mesmo período, verifica-se que em 2000 representava $0,7 \%$, passando a representar 1,2\% em 2011, aumento de 58,0\%.

Os cinco maiores estados produtores de soja do Brasil em 2011, responderam por $81 \%$ da produção nacional: Mato Grosso (28\%), Paraná (21\%), Rio Grande do Sul (16\%), Goiás (10\%) e Mato Grosso do Sul (7\%), conforme Figura 1. Nota-se que o Centro-Oeste representou $45 \%$ da produção nacional, seguido pela região Sul com $37 \%$.

Em parte, os indicadores apresentados podem ser explicados pelo aumento da área plantada, sendo que os estados de Mato Grosso, Goiás, e Paraná, a taxa de crescimento ultrapassa três dígitos. Somente no estado de Mato Grosso o aumento nos últimos 20 anos foi de 316\%. Para o mesmo período, Goiás cresceu (156\%), Paraná (101\%), Mato Grosso do Sul (37\%) e Rio Grande do Sul (16\%), segundo o IBGE (2014). A produtividade da oleaginosa também apresentou indicadores virtuosos. O estado de Goiás aumentou a produtividade em $139 \%$, seguido pelo Estado de Mato Grosso do Sul (82\%), Paraná (66\%) e Mato Grosso (63\%) (SANTOS, 2012; IBGE, 2014).

Segundo estimativas do Ministério da Agricultura, Pecuária e Abastecimento - MAPA, a produtividade deverá se manter estável nos próximos 11 anos (MAPA, 2011). Por outro lado, a produção de soja no Brasil em 2022 deverá atingir 123 milhões de toneladas, o que representará um acréscimo de $25 \%$ em relação à produção de 2010/11. Para atingir este patamar, o crescimento nos próximos 11 anos deverá ser superior a 2,0\% ao ano, índice inferior ao apresentado nos últimos 22 anos de 5,0\% ao ano (FAO, 2014).

No mesmo período, o consumo deverá crescer $1,8 \%$ ao ano, passando de 37 milhões de toneladas em 2010/11 para 45 milhões em 2020/21. As exportações deverão crescer mais que a produção e o consumo, sendo a taxa projetada de $3,0 \%$ ao ano, aumentando de 29 milhões em 2010/11 para 40 milhões em 2020/21. 
Figura 1. Participação estadual na produção de soja do Brasil entre 1990 a 2011.

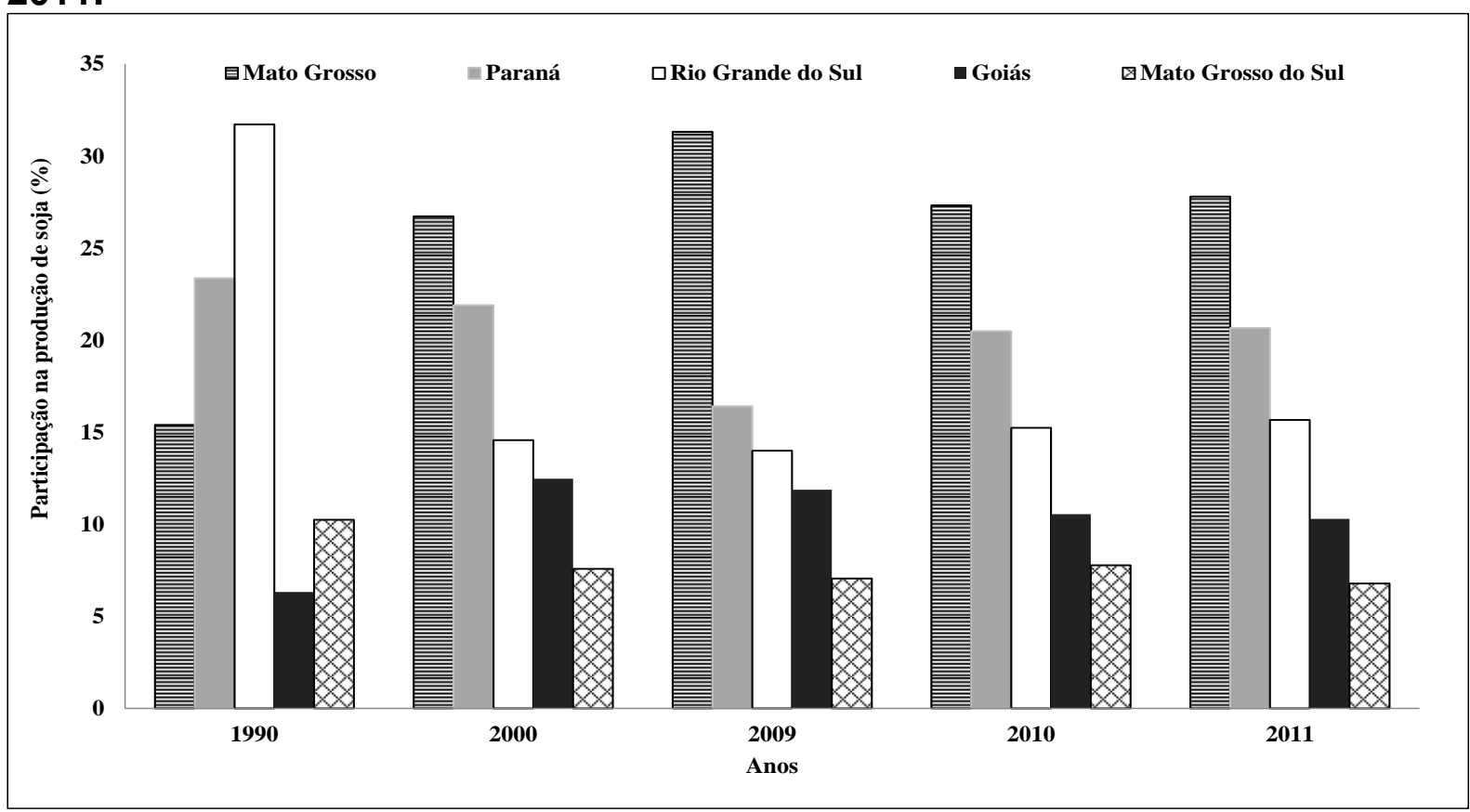

Fonte: Elaboração própria com dados do IBGE (2014).

Por meio da combinação da ocupação de terras de pastagens e expansão de fronteiras agrícolas, tais como "MATOPIBA" - estados de Maranhão, Tocantins, Piauí e Bahia - as áreas plantadas deverão apresentar um acréscimo de $2 \%$ ao ano, passando de 24 milhões de hectares em 2010/11 para 30 milhões em 2020/21, representado um acréscimo de aproximadamente 6 milhões de hectares. Isso é evidenciado pelo relatório da Associação Brasileira das Indústrias de Óleos Vegetais:

O Complexo Soja tem um papel importante no desenvolvimento da economia brasileira. Em 2011, foram movimentados cerca de 24 bilhões de dólares apenas nas exportações de soja, farelo e óleo. A sojicultura brasileira gera 1,5 milhão de empregos em 17 Estados do País. O crescimento dos setores envolvidos com a soja por meio de investimentos em tecnologias, novas áreas agrícolas e indústrias de processamento de grãos e refino de óleos tem promovido resultados positivos não apenas em volumes operados, mas também na melhoria de vida da população. A comparação entre as duas últimas pesquisas do Índice de Desenvolvimento Humano - IDH (medido entre 0 e 1) realizadas pelo Programa das Nações Unidas para 0 Desenvolvimento - PNUD, órgão da Organização das Nações Unidas, revela um aumento vigoroso da qualidade de vida nos municípios em que a soja desempenha importante papel econômico e social. Os efeitos positivos promovidos pela soja e a indústria se traduzem em mais empregos, fontes de renda e melhoria na qualidade de serviços por meio da ampliação de investimentos em educação, capacitação profissional e cidadania. ASSOCIAÇÃO BRASILEIRA DAS INDUSTRIAS DE ÓLEOS VEGETAIS - ABIOVE (2013). 
Assim, torna-se evidente que as transformações tecnológicas incorporaram importantes alterações nos meios de produção de soja no Brasil, projetando-a entre as maiores e mais competitivas culturas do mundo. Todavia, esse crescimento não está sendo acompanhado por toda a cadeia produtiva, inclusive pela Capacidade Estática de Armazenagem, termo técnico utilizado a explicar a quantidade de grãos que cabe de uma só vez dentro de uma unidade armazenadora (AZEVEDO et.al., 2008).

Em todo o mundo é constatada a perda de grande volume alimentar ocasionados por métodos inadequados de manuseio e armazenamento. Para a preservação e conservação dos alimentos é necessária a utilização de tecnologias que tragam a limpeza, secagem, tratamento fitossanitário e classificação, criando um cenário de disponibilidade nutricional, estabelecendo um fluxo lógico ao escoamento da safra, bem como armazenamento do excedente - fatores de desenvolvimento econômico.

Os grãos pertencem à categoria de deteriorável e não perecível e em condições de armazenamento adequadas mantém por muito tempo seu formato e suas qualidades nutricionais, visto ser requisitos básicos para a transação comercial. A Companhia Nacional de Abastecimento - CONAB classifica os silos de armazenamento em duas categorias: a convencional e a granel. O primeiro é adequado para armazenar produtos, como café, arroz e algodão, normalmente em sacos, fardos, caixas e pallets, dentre outras. Já a segunda categoria é caracterizada pelo abandono do uso de sacaria, alinhado com as diretrizes da Lei 9.973, de 29 de maio de 2000, que dispõe sobre 0 sistema de armazenagem dos produtos agropecuários (WEBER, 2005).

A Organização das Nações Unidas para Alimentação e Agricultura (FAO), aconselha como número mínimo de armazéns em cada região, a soma de toda a produção daquela região, mais uma margem de $20 \%$ de segurança para que não ocorra déficit em caso de superproduções. No Brasil, a capacidade estática de armazenagem em forma de armazém a granel cadastrado na CONAB é de 123 milhões de toneladas, sendo 42\% dessa capacidade localizada na região Sul do Brasil. São 6.095 armazéns, com disponibilidade de armazenamento para 51 milhões de toneladas. A região Centro-Oeste possui 38\% da capacidade estática, sendo 3.055 armazéns com disponibilidade de armazenamento para 46 milhões de toneladas. $\mathrm{Na}$ região Sudeste, contatou-se 12\%, sendo 964 armazéns com capacidade de 14 milhões de toneladas (LEITE, 2013).

Ao analisar a capacidade estatística de armazenamento, identificou-se que $61 \%$ são preenchidas somente com a produção da soja. Em alguns estados este número é mais agravante: no Mato Grosso, o indicador salta para $76 \%$; Mato Grosso do Sul (71\%); Paraná (67\%) e Goiás (65\%). Atualmente, não existe uma estatística sobre os armazéns não cadastrados junto a CONAB, estima-se que o indicador é menor que $5 \%$.

A deficiência de armazenagem e as filas nas cooperativas têm forçado os agricultores brasileiros a pagarem custos maiores de transporte e a retardar a colheita para evitar o processo de fermentação no transporte, perdas que somadas atingem $10 \%$ da produção. Soma-se ainda ao prejuízo a falta de armazéns que obrigam o escoamento da produção no momento da colheita, ocasionando cenários de congestionamentos nas rodovias, ferrovias e perdas na comercialização. 
Como forma de ponderar, ao analisar os indicadores de armazenagem dos EUA é possível encontrar armazéns nas propriedades e a soma da capacidade instalada de uma safra e meia. Ao comparar a matriz de transporte de países com as mesmas dimensões geográficas ao do Brasil, notar-se-á o longo caminho de investimento a percorrer, como descrito por Pontes, Carmo e Porto (2009) no qual:

> Rússia: ferroviário (81\%), rodoviário (8\%) e hidroviário (11\%);

$>$ Canadá: ferroviário (46\%), rodoviário (43\%) e hidroviário (11\%);

$>$ Austrália: ferroviário (43\%), rodoviário (53\%) e hidroviário (4\%);

$>$ EUA: ferroviário $(43 \%)$, rodoviário $(32 \%)$ e hidroviário $(25 \%)$;

$>$ China: ferroviário (37\%), rodoviário $(50 \%)$ e hidroviário (14\%);

> Brasil: ferroviário (21\%), rodoviário $(61 \%)$ e hidroviário (14\%).

Considerando o aumento da importância da produção da $2^{\mathrm{a}}$ safra (milho), o crescimento da produção de produtos, como transgênicos e orgânicos, que demandam separação por cédulas específicas no armazenamento, é concluso que há um cenário de vazio logístico, aumento de custos e perda de competitividade (WEBER, 2005; AZEVEDO et.al., 2008; PONTES, CARMO e PORTO, 2009; ASSUMPÇÃO e MORAIS, 2013; ESTADÃO, 2013).

Em face deste contexto, o objetivo deste estudo foi realizar uma análise espacial e temporal da produção de soja, e a capacidade estática dos armazéns de grãos no estado de Mato Grosso, Brasil.

\section{MATERIAIS E MÉTODOS}

Para este estudo foi realizado um levantamento da capacidade estática dos armazéns a granel, área plantada em hectares e a quantidade produzida de soja no Estado de Mato Grosso, junto às instituições:

- FAO - Food and Agriculture Organization;

- MAPA - Ministério da Agricultura, Pecuária e Abastecimento;

- BACEN - Banco Central do Brasil;

- CONAB - Companhia Nacional de Abastecimento;

- IBGE - Instituto Brasileiro de Geografia e Estatística;

Junto com os dados da CONAB e da revisão da literatura com os levantamentos de Weber (2005), Azevedo et.al. (2008), Assumpção e Morais (2013), Paula e Faveret Filho (2013) foi identificada a capacidade estática dos armazéns a granel e suas classificações. O objetivo é usar esses dados para analisar e comprovar por meio das dimensões espaciais as regiões deficitárias no Estado de_Mato Grosso.

As variáveis da área cultivada e produção de soja no estado de Mato Grosso, além da capacidade estática de armazenamento, foram atribuídas informações sobre sua localização geográfica - latitude e longitude de cada localidade, de acordo com dados oficiais disponibilizados pelo IBGE. Isso permite que tais informações fossem exportadas para um ambiente de Sistemas de Informações Geográficas. Em relação ao programa de 
geoprocessamento, decidiu-se pelo uso de um software livre. Fez-se então uso do Quantum GIS (NANNI et al., 2013).

\section{RESULTADOS E DISCUSSÃO}

Confinada ao não uso das dimensões espaciais pela teoria econômica tradicional, o estudo da geografia econômica utilizada por Diniz (2012) e utilizado nesta pesquisa, busca explicar a micro organização espacial dos agentes e elucidar as razões pelas quais determinadas atividades, situadas em determinados lugares, têm mais sucesso do que em outros. A relevância dessa pesquisa é inerente ao setor que exerce fortes transbordamentos para 0 restante da economia, desempenhando função importante no desenvolvimento econômico.

As análises espaciais de área cultivada de soja no estado de Mato Grosso, entre os anos de 1990 a 2010, estão representadas na Figura 2. Observa-se que as áreas cultivadas tiveram início nos entornos das estradas federais, procedimento estratégico para o escoamento da produção. Em 1990, apenas o município de Campo Novo do Parecis teve área cultivada acima de 150 mil hectares, representando $13 \%$ da área cultivada no estado. Outros municípios com uma boa representativa participação foram: Sorriso $(9 \%)$, Primavera do Leste (9\%), Itiquira (8\%), Campo Verde (7\%) e Diamantino (6\%) (IBGE, 2014).

No ano 2000, são evidenciadas novas áreas de cultivo, revelando espacialmente os sinais de rompimento da cadeia de plantio da soja no estado do Mato Grosso, maior produtor de soja do Brasil (Figura 2). Constatou-se que o número de municípios com área de cultivo entre 150 a 300 mil hectares hectares saltou para seis, sendo: Sapezal, Campo Novo do Parecis, Diamantino, Nova Mutum, Lucas do Rio Verde e Primavera do Leste. O destaque foi para o município de Sorriso, que se tornou o maior produtor do estado de Mato Grosso.

Em números absolutos, analisando a participação na produção estadual, o município de Sorriso apresentou um aumento de $157 \%$ na área cultivada, passando de 140 mil hectares (9\%) em 1990 para 360 mil hectares (12\%), em 2000. Diamantino teve crescimento de $100 \%$ na área cultivada, passando de 100 mil hectares (6\%) em 1990 para 200 mil hectares (7\%). Campos Novo do Parecis aumentou $45 \%$ sua área, passando de 200 mil hectares (13\%) em 1990 para 291 mil hectares (10\%) em 2000. Primavera do Leste foi de $24 \%$, passando de 136 mil hectares (9\%) em 1990 para 170 mil hectares (6\%) em 2000 (IBGE, 2014). O ranking estadual da área de cultivo da Soja ficou da seguinte forma:

- Sorriso: $2^{\circ}$ lugar ano 1990 e $1^{\circ}$ lugar ano 2000;

- Campo Novo do Parecis: $1^{\circ}$ lugar ano 1990 e $2^{\circ}$ lugar ano 2000;

- Diamantino: $6^{\circ}$ lugar ano 1990 e $4^{\circ}$ lugar ano 2000;

- Primavera do Leste: $3^{\circ}$ lugar ano 1990 e $6^{\circ}$ lugar ano 2000;

- Itiquira: $4^{\circ}$ lugar ano 1990 e $9^{\circ}$ lugar ano 2000;

- Diamantino: $5^{\circ}$ lugar ano 1990 e $11^{\circ}$ lugar ano 2000.

A área plantada de soja no ano de 2010 comparada ao ano 2000 apresentou um crescimento de $114 \%$, ou seja, um acréscimo de mais de 3 
milhões de hectares. O estado apresentou 139 municípios com área cultivada de até 150 mil hectares; 10 municípios com áreas entre 150 a 300 mil hectares; três municípios com áreas entre 300 a 450 mil hectares e apenas o município de Sorriso, com área superior a 450 mil hectares.

Na Figura 2, no ano 2000, nota-se um considerável avanço da cultura de soja, presente em quase todo estado, acentuando-se no meio norte em direção do leste para oeste. Os resultados no ano de 2010 mostram ausência ou pouca expressividade da cultura de soja nas regiões mais ao sul ou ao extremo norte do estado do Mato Grosso.

Este resultado corrobora com os estudos já publicados pela Empresa Braisleira de Pesquisa Agropecuária (Embrapa), que ao considerar a diversidade de ecossistemas, solo e clima, realizou em 2012 um modelo delineador para a indicação de cultivares de soja para o Brasil, concluindo que parte da região sul e o extremo norte do Estado do Mato Grosso são áreas não recomendadas para testes de cultivares de soja (KASTER e FARIAS, 2012; BROGIN et al., 2013). 

2010.

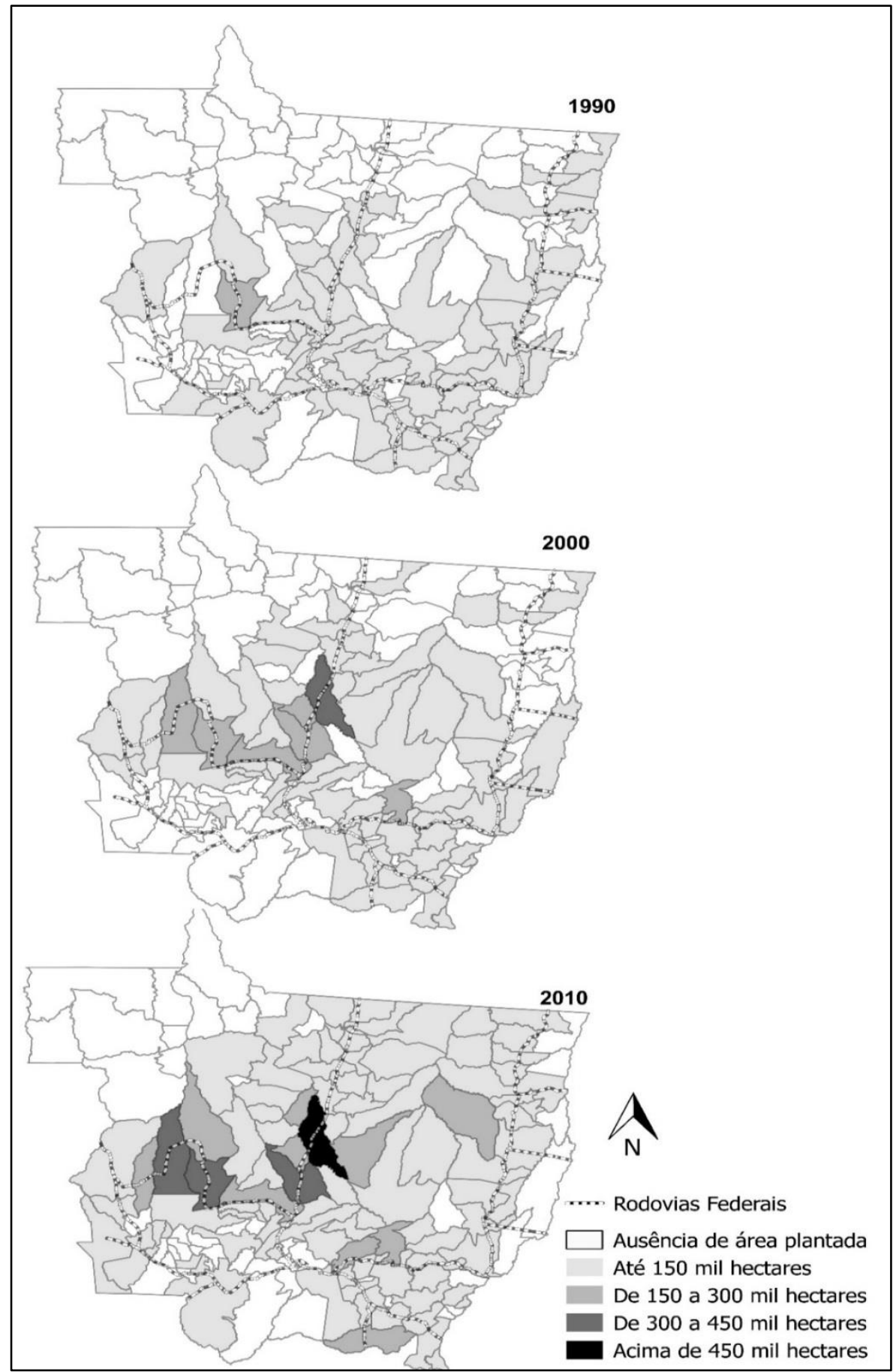

Fonte: Elaboração própria com dados do IBGE.

O clima, logística e armazenamento podem se tornar fatores limitantes para a expansão e competitividade da cultura de soja no estado. As ações de alguns agricultores em 2011 podem ser explicadas, em parte, através dos indicadores da produtividade do ano 2010. Segundo o IBGE (2011), a soja 
precoce sofreu com a seca durante o plantio nas áreas com o maior nível de produção no estado. Estas informações, uma vez espacializadas, foram representadas na Figura 3.

Figura 3. Produção de soja no estado do Mato Grosso 2010.

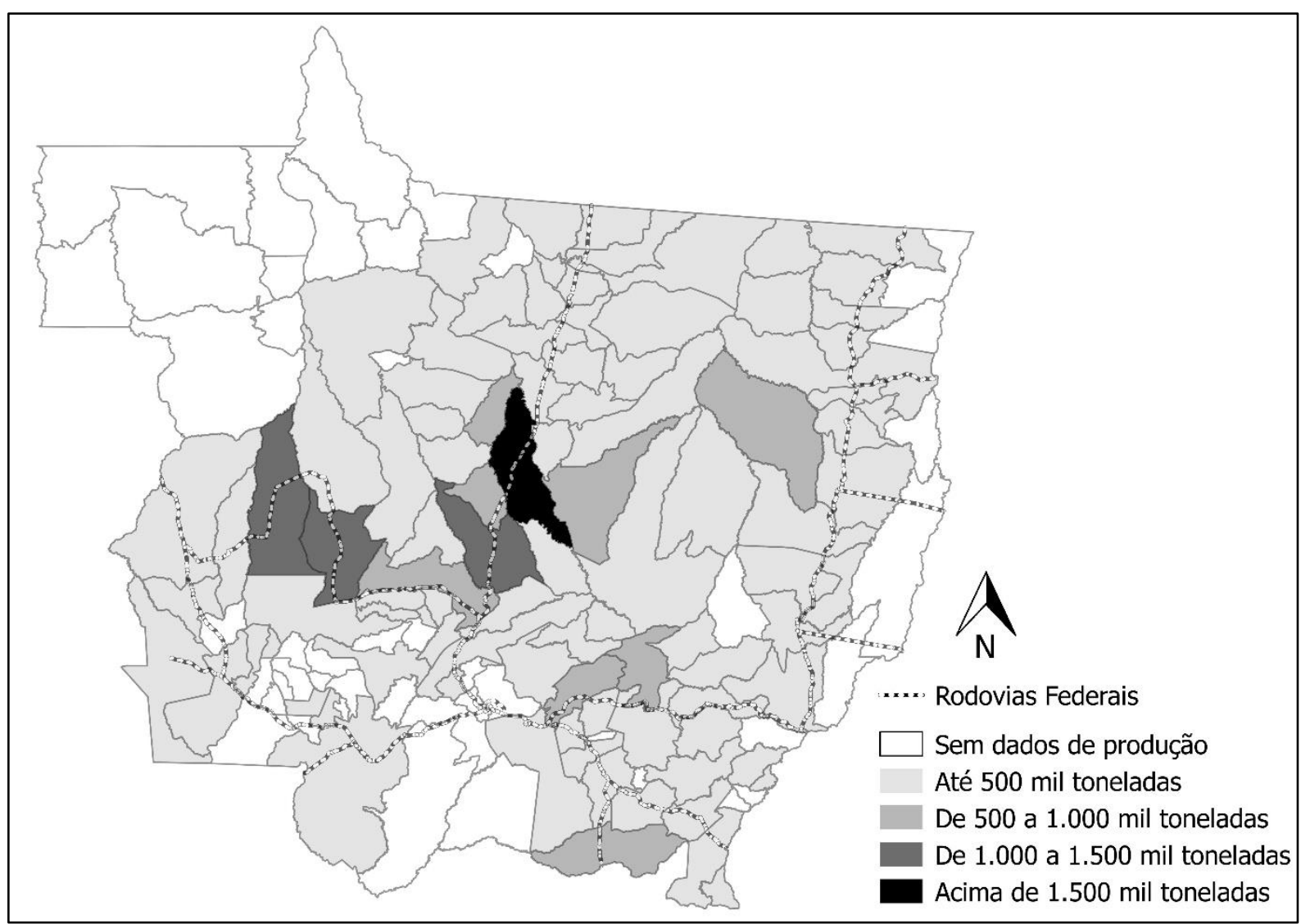

Fonte: Elaboração própria com dados do IBGE.

Houve diminuição de 2\% na produtividade média no Estado em 2010 em relação ao ano de 2009, sendo que o município de Campos de Júlio apresentou queda de $18 \%$. Já os munícipios de Sinop, Diamantino, Sapezal as quedas foram de $7 \%$, e Campo Novo do Parecis de $2 \%$.

Perante a esse cenário, mesmo o estado de Mato Grosso apresentando crescimento de $4 \%$ na área de plantio, alguns municípios exibiram queda na área no ano 2011 em relação ao anterior: Diamantino (-12\%), Campos de Júlio $(-8 \%)$, Sapezal (-6\%), Campo Novo do Parecis, Lucas do Rio Verde e Sinop ($4 \%)$, Itiquira (-3\%), Novo São Joaquim (-2\%) (IBGE, 2014).

Outra situação problema é a falta de armazéns para estocar os produtos, principalmente nos períodos de safras (ABRAMILHO, 2011). Ao examinar a produção de soja de 2011 e comparando-a com a Capacidade Estática dos Armazéns a Granel de 2013 (Figura 4), nota-se que entre as microrregiões (Figura 5) que produzem acima de um milhão de tonelada ( $84 \%$ da produção estadual) constatou-se que Arinos - formada pelos municípios de Tabaporã, São José do Rio Claro, Nova Maringá, Porto dos Gaúchos e Juara - apresentou taxa de ocupação dos armazéns em $168 \%$. Assim, a quantidade produzida da soja nesta região (1.268 mil toneladas - 6\%) é capaz de preencher a 
capacidade estática dos armazéns a granel (756 mil toneladas), apresentando um déficit de $68 \%$.

Figura 4. Capacidade Estática de Armazenamento de soja no estado de Mato Grosso em 2013.

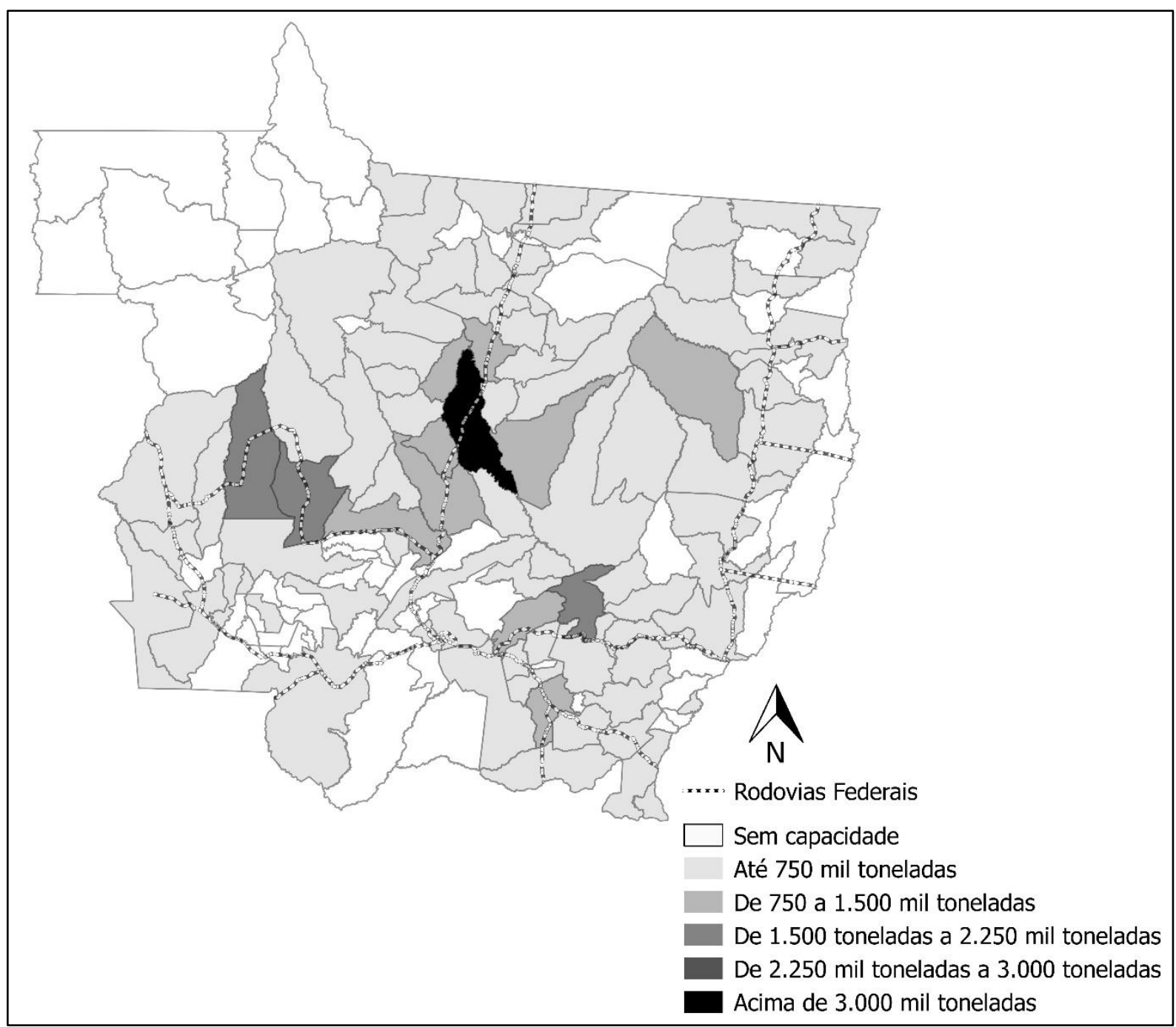

Fonte: Elaboração própria com dados do IBGE.

O quadro agrava-se ao analisar por município (IBGE, 2011):

- Nova Maringá: 420 mil toneladas, capacidade estática 167 mil toneladas - taxa de ocupação de $251 \%$;

- São José do Rio Claro: 318 mil toneladas, capacidade estática 190 mil toneladas - taxa de ocupação de 167\%;

- Porto dos Gaúchos: 221 mil toneladas, capacidade estática 141 mil toneladas - taxa de ocupação de 157\%;

- Tabaporã: 307 mil toneladas, capacidade estática 254 mil toneladas taxa de ocupação de $121 \%$.

A microrregião de Canarana produziu 2.124 mil toneladas (10\%), enquanto a capacidade estátista de armazenagem é de 1.712 mil toneladas $124 \%$ de taxa de ocupação. 
Ao analisar os municípios pertencentes à microrregião vê-se que a situação é preocupante (IBGE, 2011):

- Novo São Joaquim: 207 mil toneladas, capacidade estática 73 mil toneladas - taxa de ocupação de $284 \%$;

- Nova Xavantina: 120 mil toneladas, capacidade estática 44 mil toneladas - taxa de ocupação de $269 \%$;

- Santo Antonio do Leste: 400 mil toneladas, capacidade estática 216 mil toneladas - taxa de ocupação de $185 \%$;

- Canarana: 406 mil toneladas, capacidade estática 335 mil toneladas taxa de ocupação de $121 \%$;

- Querência: 841 mil toneladas, capacidade estática 812 mil toneladas taxa de ocupação de 104\%;

- Água Boa: 148 mil toneladas, capacidade estática 229 mil toneladas taxa de ocupação de $65 \%$.

Figura 5. Microrregiões do Estado do Mato Grosso, Brasil.

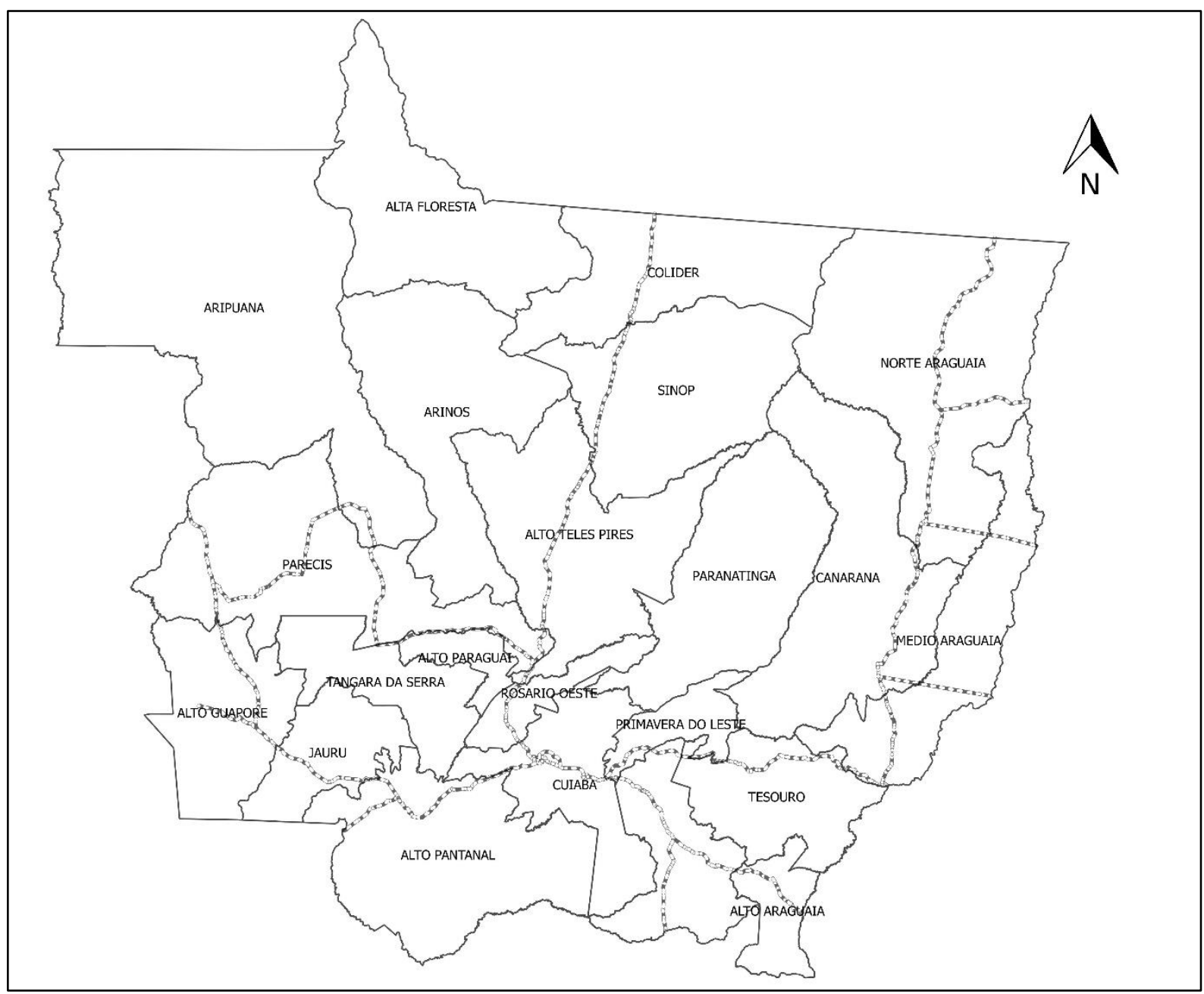

Fonte: Elaboração própria.

A microrregião de Alto Teles Pires, maior produtora de soja, 6.612 mil toneladas (32\%), apresentou capacidade estática de 8.994 mil toneladas, taxa 
de ocupação de $74 \%$. Ao analisar os municípios pertencentes à microrregião, também se verifica grande demanda por armazéns (IBGE, 2011):

- Santa Rita do Trivelato: 544 mil toneladas, capacidade estática 320 mil toneladas - taxa de ocupação de $170 \%$;

- Itanhangá: 156 mil toneladas, capacidade estática 97 mil toneladas taxa de ocupação de $160 \%$;

- Tapurah: 494 mil toneladas, capacidade estática 438 mil toneladas taxa de ocupação de $113 \%$;

- Nova Ubiratã: 913 mil toneladas, capacidade estática 887 mil toneladas - taxa de ocupação de $103 \%$;

- Nova Mutum: 1.161 mil toneladas, capacidade estática 1.362 mil toneladas - taxa de ocupação de $85 \%$;

- Ipiranga do Norte: 495 mil toneladas, capacidade estática 799 mil toneladas - taxa de ocupação de $85 \%$;

- Sorriso: 2.088 mil toneladas, capacidade estática 3.616 mil toneladas taxa de ocupação de $58 \%$;

- Lucas do Rio Verde: 757 mil toneladas, capacidade estática 1.472 mil toneladas - taxa de ocupação de $51 \%$.

A microrregião de Parecis foi a $2^{\circ}$ produtora de soja no estado, com 3.523 mil toneladas (17\%) e capacidade estátista de armazenagem de 5.068 mil toneladas, $70 \%$ de taxa de ocupação. Nesta região, todos os municipios possuem a taxa de ocupação inferiores a 100\% (IBGE, 2011):

- Campo Novo do Parecis: 990 mil toneladas, capacidade estática 1.650 mil toneladas - taxa de ocupação de $60 \%$;

- Sapezal: 1.090 mil toneladas, capacidade estática 1.581 mil toneladas taxa de ocupação de $69 \%$;

- Diamantino: 826 mil toneladas, capacidade estática 935 mil toneladas taxa de ocupação de $88 \%$;

- Campos de Júlio: 493 mil toneladas, capacidade estática 701 mil toneladas - taxa de ocupação de $70 \%$;

- Campos de Júlio: 122 mil toneladas, capacidade estática 199 mil toneladas - taxa de ocupação de $62 \%$.

A microrregião de Rondonópolis (IBGE, 2011), produziu 1.251 mil toneladas (6\%), com capacidade estátista de armazenagem é de 1.970 mil toneladas - $64 \%$ de taxa de ocupação. Ao analisar os municípios pertencentes à microrregião, pode-se concluir que aparentemente existem armazéns sobrando em parte deles, porém, outros municípios com grande falta de armazéns.

- Dom Aquino: 84 mil toneladas, capacidade estática 18 mil toneladas taxa de ocupação de 454\%;

- Juscimeira: 96 mil toneladas, capacidade estática 22 mil toneladas taxa de ocupação de $422 \%$;

- Jaciara: 102 mil toneladas, capacidade estática 62 mil toneladas - taxa de ocupação de 164\%; 
- Itiquira: 608 mil toneladas, capacidade estática 554 mil toneladas - taxa de ocupação de $110 \%$;

- Pedra Preta: 132 mil toneladas, capacidade estática 336 mil toneladas taxa de ocupação de 39\%;

- Rondonópolis: 227 mil toneladas, capacidade estática 975 mil toneladas - taxa de ocupação de $23 \%$.

Ainda na Figura 5, a microrregião de Sinop, produziu 1.389 mil toneladas (7\%), a capacidade estátista de armazenagem é de 2.201 mil toneladas - $63 \%$ de taxa de ocupação (IBGE, 2011). Ao analisar os municípios pertencentes à microrregião, verifica-se que:

- Vera: 431 mil toneladas, capacidade estática 269 mil toneladas - taxa de ocupação de 160\%;

- Santa Carmem: 232 mil toneladas, capacidade estática 195 mil toneladas - taxa de ocupação de 119\%;

- Cláudia: 136 mil toneladas, capacidade estática 134 mil toneladas - taxa de ocupação de 101\%;

- Feliz Natal: 159 mil toneladas, capacidade estática 173 mil toneladas taxa de ocupação de 92\%;

- Itaúba: 36 mil toneladas, capacidade estática 41 mil toneladas - taxa de ocupação de 88\%;

- União do Sul: 35 mil toneladas, capacidade estática 46 mil toneladas taxa de ocupação de 75\%;

- Sinop: 356 mil toneladas, capacidade estática 1.337 mil toneladas - taxa de ocupação de $27 \%$.

Por fim, a microrregião de Primavera do Leste, que possui o melhor índice do Estado, teve $43 \%$ de taxa de ocupação nos armazéns e capacidade estátista de armazenagem de 3.080 mil toneladas e a produção de 1.317 mil toneladas (6\%). Ao analisar os municípios pertencentes desta microrregião, verifica-se que:

- Campo Verde: 564 mil toneladas, capacidade estática 853 mil toneladas - taxa de ocupação de $66 \%$;

- Primavera do Leste: 753 mil toneladas, capacidade estática 2.226 mil toneladas - taxa de ocupação de $34 \%$.

A produção de soja no Estado do Mato Grosso no ano de 2011 foi de 20,8 milhões toneladas sendo que as principais microrregiões foram:

- Microrregião do Alto do Teles Pires (32\%) - 6.612 milhões toneladas;

- Microrregião de Parecis (17\%) - 3.523 milhões de toneladas;

- Microrregião do Canarana (10\%) - 2.124 milhões de toneladas;

- Microrregião de Sinop (7\%) - 1.389 milhões de toneladas;

- Microrregião de Arinos (6\%) - 1.268 milhões de toneladas;

- Microrregião de Rondonópolis (6\%) - 1.251 milhões de toneladas. 
As áreas por microrregião e municípios com déficit de armazenagem que apresentam indicadores para a construção e/ou ampliação de armazéns estáticos foram:

> Microrregião de Arinos: déficit (68\%);

○ Nova Maringá: déficit (151\%);

- São José do Rio Claro: déficit (67\%);

- Porto dos Gaúchos: déficit (57\%);

○ Tabaporã: déficit (21\%).

> Microrregião de Canarana apresentou um déficit de armazenagem de $24 \%$;

○ Novo São Joaquim: déficit (184\%);

- Nova Xavantina: déficit (169\%);

- Santo Antônio do Leste: déficit (85\%);

- Canarana: déficit (21\%);

○ Querência: déficit (4\%).

\section{CONSIDERAÇÕES FINAIS}

No transporte rodoviário, há insuficiência de veículos para o transporte da safra, infraestrutura degradada e malha viária inadequada. No transporte ferroviário, temos deficiência na integração operacional das malhas ocasionadas por diferenças de bitolas e invasão dos centros urbanos aos acessos dos portos. Nas faixas de domínio das ferrovias, malha viária pouca extensa de vagões, locomotivas insuficientes e com idade avançada. $\mathrm{Na}$ logística das hidrovias, é identificada a ausência de integração com outros modais de transporte, restrições de consistência na ausência de barcaças e quantidades de eclusas insuficientes. Além disso, faltam investimentos, planejamentos e implantações de políticas públicas que criem racionalização nos processos e fluxos de pós-colheita. Desta forma, a expansão planejada dos armazéns a granel irá minimizar as perdas no escoamento da produção, principalmente para o médio e o pequeno produtor, que normalmente não possuem estrutura de armazenagem e defrontam com custos com armazéns de terceiros ou ainda fazem vendas após a colheita (PONTES, CARMO e PORTO, 2009).

Novas projeções realizadas pelo Ministério da Agricultura, Pecuária e Abastecimento (MAPA) afirmam que a Soja Grão apresenta expectativa, no Brasil, de crescimento na produção anual no período de 2014/15 a 2024/25 de $3,04 \%$. Deverá ocorrer um crescimento de 30,8\% na área plantada, com 69 milhões de toneladas e participação de 45,9\% no comércio mundial. No Estado de Mato Grosso, a área plantada apresentará um crescimento maior que a média nacional, com variação de $38,3 \%$ e a produção deverá crescer $39,7 \%$ (MAPA, 2015).

Por um lado, crescimento da área e produção, de outro a rentabilidade. A soja no Estado de Mato Grosso é competitiva e com menor aversão ao risco, sendo uma cultura com consolidada participação na safra de verão (MASCARENHAS et al., 1993; MELO, SILVA e ESPERANCICNI, 2013). 
Por fim, confirma-se que as estruturas dos armazéns estáticos a granel não são suficientes para atender tanto a produção atual como ao crescimento potencial da soja do Estado de Mato Grosso.

\section{REFERÊNCIAS}

ABRAMILHO. Falta de infraestrutura afeta o escoamento de grãos no MT. 2011. DCI - SÃO PAULO - (SP) - 22/02/2011 - Agronegócios. Disponível em: <http://abramilho.org.br/noticias.php?cod=1407>. Acesso em: 07 jan. 2014.

ABIOVE - ASSOCIAÇÃO BRASILEIRA DAS INDUSTRIAS DE ÓLEOS VEGETAIS. Importância Econômica e Social. Disponível em: <http://www.w3.org/TR/html401/interact/forms.html>. Acesso em: 20 set. 2013.

ASSUMPÇÃO, R. C.; MORAIS, G. Especialistas preveem falta de armazéns para 40 milhões de toneladas da safra. Câmara dos Deputados Reportagem - Ginny Morais - 28/05/2013. Disponível em: $<$ http://www2.camara.leg.br/camaranoticias/noticias/AGROPECUARIA/443564ESPECIALISTAS-PREVEEM-FALTA-DE-ARMAZENS-PARA-40-MILHOESDE-TONELADAS-DA-SAFRA.html>. Acesso em: 25 out. 2013.

AZEVEDO, L. F.; OliveiRA, T. P. de; PORTO, A. G.; SILVA, F. S. da. A Capacidade Estática de Armazenamento de Grãos no Brasil. 2008. XXVIII ENCONTRO NACIONAL DE ENGENHARIA DE PRODUÇÃO - A integração de cadeias produtivas com a abordagem da manufatura sustentável. Rio de Janeiro, RJ, Brasil, 13 a 16 de outubro de 2008. Disponível em: $<$ http://www.abepro.org.br/biblioteca/enegep2008 TN STP 069 492 11589.p $\underline{\mathrm{df}}>$. Acesso em: 23 jan. 2014.

BACEN - Banco Central do Brasil. SGS - Sistema Gerenciador de Séries Temporais. <https://www3.bcb.gov.br/sgspub/localizarseries/localizarSeries.do?method=pr epararTelaLocalizarSeries>. 2014.

BERTRAND, J. P.; LAURENT, C.; LECLERCQ, V. O mundo da Soja. Tradução de Lólio Lourenço de Oliveira. São Paulo: Hucitec, 1987, 139p.

BROGIN, R. L.; BOTELHO, F. J. E.; GODINHO, V. de P. C.; UTUMI, M. M. Cultivares Convencionais de Soja: Macrorregiões 3, 4 e 5. 2013. Empresa Brasileira de Pesquisa Agropecuária - Ministério da Agricultura, Pecuária e Abastecimento - Embrapa Soja - Londrina, PR 2013. Disponível em: $<$ https://www.embrapa.br/soja/busca-de-publicacoes/-

/publicacao/954281/cultivares-convencionais-de-soja-macrorregioes-3-4-e-5>. Acesso em: 02 dez. 2014.

CONAB - Companhia Nacional de Abastecimento. Estatísticas Séries históricas: <http://www.conab.gov.br/conteudos.php?a=1252\&t=2>. 2014.

DINIZ, S. S. Análise espacial da produtividade da laranja nos municípios do Estado de São Paulo: 2002-2010. 2012. 118p. Dissertação (Mestrado) - 
Curso de Mestrado em Economia Regional, Departamento de Centro de Estudos Sociais Aplicados - Programa de Pós-graduação em Economia Regional (PPE), Universidade Estadual de Londrina, Londrina, Paraná, 2012.

EMBRAPA TRIGO. XXXIX Reunião de Pesquisa de Soja na Região Sul: 24 a 26 de julho de 2012. ISSN 1984-0713 - Empresa Brasileira de Pesquisa Agropecuária Embrapa Trigo - Passo Fundo, RS - 2012. Atas e resumos. Disponível em: $<$ http://ainfo.cnptia.embrapa.br/digital/bitstream/item/79907/1/atas-e-resumosreuniao-soja-2012.pdf>. Acesso em: 18 nov.2013

ESTADÃO. Falta de infraestrutura de armazéns prejudica agronegócio brasileiro. 2013. Publicado na terça-feira, 5 de novembro de 2013, as 14:52. Disponível em: <http://www.fecomercio.com.br/blog/2013/11/05/falta-deinfraestrutura-de-armazens-prejudica-agronegocio-brasileiro/>. Acesso em: 13 jan. 2014.

FERNANDES FILHO, J. F.; BELIK, W. A política de tributação na exportação do complexo soja pelo Brasil: Transformação e resultados. 2010. Sociedade Brasileira de Economia, Administração e Sociologia Rural. Disponível em: <http://www.sober.org.br/palestra/15/662.pdf>. Acesso em: 25 jul. 2010.

FAO - Food and Agriculture Organization of the United Nations. FAOSTAT Domains: <http://faostat3.fao.org/faostat-gateway/go/to/download/Q/*/S > 2014.

FUKUI, T. de J.; LOPES, R. L. A expansão do cultivo da soja na área de influência da BR 163 e os impactos nas regiões produtoras do estado do Paraná. Universidade Estadual de Maringá (UEM). p. 1-24 Disponível em: $<$ http://www.ecopar.ufpr.br/artigos/a4 077.pdf>. Acesso em: 19 set. 2013.

IBGE - Instituto Brasileiro de Geografia e Estatística. Sistema IBGE de Recuperação Automática (SIDRA): <http://www.sidra.ibge.gov.br/>. 2014. IBGE - Instituto Brasileiro de Geografia e Estatística. Em janeiro, IBGE prevê safra de grãos 1,8\% menor que a de 2010. 09 de fevereiro de 2011. Comunicação Social. Disponível em: $<$ http://saladeimprensa.ibge.gov.br/noticias?view=noticia\&id=1\&busca=1\&idnoti cia=1819 >. Acesso em: 02 jan. 2014.

KASTER, M. e FARIAS, J. R. B. Regionalização dos testes de valor de cultivo e uso e da indicação de cultivares de soja - terceira aproximação. Embrapa Soja. Documentos/Embrapa Soja, n. 330, 69p. Londrina. 2012.

LEITE, G. L. D. Capacidade de armazenamento e escoamento de grãos do Estado do Mato Grosso. UNIVERSIDADE DE BRASÍLIA - FACULDADE DE AGRONOMIA E MEDICINA VETERINÁRIA - Brasília - DF - Março / 2013 -. Disponível em: <http://www.planalto.gov.br/ccivil 03/leis/L9973.htm>. Acesso em: 20 set. 2013

MASCARENHAS, H. A. A.; NAGAI, V.; GALLO, P. B.; PEREIRA, J. C. V. N. A.; TANAKA, R. T. Sistemas de rotação de culturas de milho, algodão e soja e seu efeito sobre a produtividade. Bragantia. n.52, v.1, p. 53-61. 1993. 
MAPA-MINISTÉRIO DA AGRICULTURA PECUÁRIA E ABASTECIMENTO. Brasil Projeções do Agronegócio 2010/2011 a 2020/2021. Assessoria de Gestão Estratégica - Brasília, junho de 2011. Disponível em: $<$ http://www.agricultura.gov.br/arq editor/file/Ministerio/gestao/projecao/PROJE COES\%20DO\%20AGRONEGOCIO\%202010-11\%20a\%202020-21\%20\%202 0.pdf >. Acesso em: 25 out. 2013.

MAPA-MINISTÉRIO DA AGRICULTURA PECUÁRIA E ABASTECIMENTO. Projeções do Agronegócio 2014/2015 a 2024/2025. Assessoria de Gestão Estratégica - Brasília, julho de 2015. Disponível em: $<$ www.agricultura.gov.br/arg editor/PROJECOES DO AGRONEGOCIO 2025 WEB.pdf>. Acesso em: 15 set. 2015.

MELO, C. O. de; SILVA, G. H. da; ESPERANCICNI, M. S. T. Análise econômica da produção de soja e de milho na safra de verão, no Estado do Paraná. Revista de Política Agrícola. Ano XXI, oํ 1, Jan./Fev./Mar. 2012, p.121-132. Disponível em: <http://www.embrapa.br/publicacoes/tecnico/revistaAgricola/rpa-2012/RPA 12012 LR.pdf>. Acesso em: 27 set. 2013.

NANNI, A. S.; DESCOVI FILHO, L.; VIRTUOSO, M. A.; MONTENEGRO, D.; WILLRICH, G.; MACHADO, P.H.; SPERB, R.; DANTAS, G. S.; CALAZANS, Y. Quantum GIS - Guia do Usuário, Versão 2.0. 'Dufour'. Disponível em: <http://qgisbrasil.org >. 291p. Acesso em: 01 de dez. 2013.

PAULA, S. R. de; FAVERET FILHO, P. Panorama do complexo Soja. BNDES. Disponível em: <http://www.inagro.org.br/publicacoes/Soja.pdf>. Acesso em: 20 set. 2013.

PESSOA, S. de A. Perspectivas de Crescimento no Longo Prazo para o Brasil: Questões em Aberto. Janeiro de 2006, no 609, ISSN 0104-8910, Fundação Getúlio Vargas, p.3-21. EPGE. Disponível em: $<$ http://bibliotecadigital.fgv.br/dspace/bitstream/handle/10438/582/2013.pdf?seq uence $=1>$. Acesso em: 25 set. 2013.

PONTES, H. L. J.; CARMO, B. B. T. do; PORTO, A. J. V. Problemas logísticos na exportação brasileira da soja em grão. Revista Eletrônica Sistemas \& Gestão, 4, (2), p.155-181. 2009. Disponível em: $<$ http://www.uff.br/sg/index.php/sg/article/view/84/0>. Acesso em: 13 jan. 2014.

SANTOS, D. B. dos. Avaliação do sistema agroindustrial da soja no Centro-Oeste. Monografia. v, 23p. 2012. Universidade de Brasília - UnB, Brasília, 2012. Disponível em: <http://hdl.handle.net/10483/3961>. Acesso em: 03 out. 2013.

WEBER, E. A. Excelência em beneficiamento e armazenagem de grãos. $1^{\text {a }}$ ed., Artiber, Canoas, 2005. 586p. 
Submetido em: 20/05/15

Aceito em: 30/10/15 